\title{
(6) OPEN ACCESS \\ Coronary heart disease and risk factors as predictors of trajectories of psychological distress from midlife to old age
}

\author{
Marianna Virtanen, ${ }^{1}$ Marko Elovainio, ${ }^{2,3}$ Kim Josefsson, ${ }^{2} \mathrm{G}$ David Batty, ${ }^{4}$ \\ Archana Singh-Manoux, ${ }^{4,5}$ Mika Kivimäki ${ }^{1,4,6}$
}

- Additional material is published online only. To view please visit the journal online (http://dx.doi.org/10.1136/ heartjnl-2016-310207)

${ }^{1}$ Finnish Institute of

Occupational Health, Helsinki, Finland

${ }^{2}$ National Institute for Health and Welfare, Helsinki, Finland ${ }^{3}$ Institute of Behavioral Sciences, University of Helsinki, Finland ${ }^{4}$ Department of Epidemiology and Public Health, University College London, London, UK Inserm U1018, Centre for Research in Epidemiology and Population Health, Villejuif, France

${ }^{6}$ Clinicum, Faculty of Medicine, University of Helsinki, Helsinki, Finland

\section{Correspondence to}

Professor Marianna Virtanen, Finnish Institute of

Occupational Health, P.O. Box 40, Helsinki FI-00251, Finland; marianna.virtanen@ttl.fi

Received 22 June 2016 Revised 7 October 2016 Accepted 12 October 2016

Published Online First

18 November 2016

\section{Linked}

- http://dx.doi.org/10.1136/ heartjnl-2016-310688

\section{CrossMark}

\section{To cite: Virtanen $M$,}

Elovainio M, Josefsson $\mathrm{K}$,

et al. Heart 2017;103:659-

665.
ABSTRACT

Objective To examine coronary heart disease (CHD) and its risk factors as predictors of long-term trajectories of psychological distress from midlife to old age. Methods In the Whitehall II cohort study, 6890 participants (4814 men, 2076 women; mean age 49.5 years) had up to seven repeat assessments of psychological distress over 21 years (mean follow-up 19 years). CHD and its risk factors (lifestyle-related risk factors, diabetes, hypertension and cholesterol) were assessed at baseline. Group-based trajectory modelling was used to identify clusters of individuals with a similar pattern of psychological distress over time.

Results We identified four trajectories of psychological distress over the follow-up: 'persistently low' $69 \%$ of the participants), 'persistently intermediate' (13\%), 'intermediate to low' (12\%) and 'persistently high' (7\%). The corresponding proportions were $60 \%, 16 \%, 13 \%$ and $11 \%$ among participants with CHD; $63 \%, 15 \%$, $12 \%$ and $10 \%$ among smokers and $63 \%, 16 \%, 12 \%$ and $10 \%$ among obese participants. In multivariable adjusted multinomial regression analyses comparing other trajectories to persistently low trajectory, prevalent CHD was associated with intermediate to low (OR $1.70,95 \% \mathrm{Cl} 1.08$ to 2.68$)$ and persistently high (OR $1.92,95 \% \mathrm{Cl} 1.16$ to 3.19$)$ trajectories. Smoking (OR $1.33,95 \% \mathrm{Cl} 1.07$ to 1.64 ; OR $1.55,95 \% \mathrm{Cl} 1.19$ to 2.04 ) and obesity (OR $1.33,95 \% \mathrm{Cl} 1.04$ to 1.70 ; OR $1.47,95 \% \mathrm{Cl} 1.07$ to 2.01) were associated with persistently intermediate and persistently high trajectories, respectively.

Conclusion CHD, smoking and obesity may have a role in the development of long-lasting psychological distress from midlife to old age.

\section{INTRODUCTION}

Depression is a major public health issue characterised by high lifetime onset, persistence over time and recurrence. ${ }^{1}$ Depression as a risk factor for incident coronary heart disease (CHD) has been extensively investigated, ${ }^{2}$ and high prevalence and incidence of depression in cardiac patients has been observed repeatedly. ${ }^{3-5}$ For the latter, depression might be a component of adjustment disorder due to a severe heart condition encountered although symptoms might be transient in nature. ${ }^{3}$ Alternatively, the 'vascular depression hypothesis' postulates that vascular pathology itself, that is, $\mathrm{CHD}$ and its risk factors, such as hypertension and hypercholesterolaemia, might predispose people to depression in later life. ${ }^{5}{ }^{6}$ Recently, subclinical common mental disorder, defined for example, as the presence of psychological distress, has also received attention because of its high prevalence in general populations and associations with future clinical depression, morbidity and mortality. ${ }^{78}$

Although there is evidence that CHD in particular and, to a lesser extent, its risk factors might increase the risk of depressive symptoms in the short term, ${ }^{5}$ their contribution to long-term trajectories of symptoms has rarely been examined and the findings are inconsistent. ${ }^{9}$ In one study of older women, self-reported myocardial infarction (MI) and hypertension predicted increasing and persistently high symptom trajectories, ${ }^{10}$ while another study of older men and women did not find such associations. $^{11}$

In this study, we sought to expand the existing knowledge on CHD and mental health by focusing on psychological distress, which includes symptoms of depression and anxiety, corresponding to a nonspecific multimorbidity condition common in older adults. ${ }^{12}$ The analyses reported here had two purposes. Using seven assessments of psychological distress over a 21-year follow-up period, we first characterised distinct trajectories of psychological distress from midlife to old age. We then examined the extent to which CHD and its risk factors predicted these trajectories.

\section{METHODS}

Participants and study design

The Whitehall II study is a prospective cohort study of British government employees initially including all London-based office staff, aged 3555 years, who were working in 20 departments at study entry, 1985-1988. ${ }^{13}$ With a response rate of $73 \%$, there were 10308 participants in the baseline examination. Since this first wave of data collection, self-completion questionnaires and clinical data have been collected from study members every 2-5 years. We used data from waves 1 to 11 , the last wave in 2012-2013 (excluding 4th and 10th due to lacking measurements of psychological distress). After complete description of the study to the participants, their written consent was obtained. Ethical approval for the Whitehall II study was obtained from the University College London Medical School and the NHS London-Harrow Health Research Authority committees on the ethics of human research. Whitehall 
II data, protocols and other metadata are available to bona fide researchers for research purposes (http://www.ucl.ac.uk/ whitehallII/data-sharing).

Of the 10308 participants at wave 1, 7575 participated and responded to questions on psychological distress at the baseline assessment of this study (wave 3, 1991-1994) and at least one other assessment during the subsequent six study waves at which psychological distress was measured. Of them, 6890 (4814 men, 2076 women; mean age 49.5 (SD 6.0) years) provided data on all covariates. The mean number of psychological distress measurements was 6.0 (SD 1.5, range 2-7) and the mean length of follow-up was 18.6 (SD 3.8) years. By the end of follow-up (31 August 2012), 557 participants (8.1\%) died. They had an average of 4.0 (SD 1.4) measurements of psychological distress at follow-up.

\section{Measurement of psychological distress}

At each examinations of the Whitehall II study (except the 4th and 10th), participants responded to the self-administered 30-item General Health Questionnaire (GHQ). ${ }^{14}$ The GHQ is a screening instrument designed to detect common mental disorder, such as depression and anxiety, and it has been shown to have high sensitivity $(78 \%, 86 \%)$ and specificity $(83 \%, 87 \%)$ for common mental disorder and depression, respectively, in the present cohort. ${ }^{15}$ Of the 30 items, 13 assess symptoms of depression (eg, 'been thinking of yourself as a worthless person'), 9 assess problems in social function (eg, 'been finding it easy to get on with other people'-reverse coding), 6 assess anxiety (eg, 'been getting scared or panicky for no good reason') and two assess sleep disturbances (eg, 'lost much sleep over worry'). Each questionnaire item denotes a specific symptom; response categories are scored as either 1 or 0 to indicate the presence of that symptom. A total score of 5 or more signals 'caseness'. ${ }^{15}$ History of psychological distress was defined as a caseness of GHQ in either wave 1 or wave 2 (1985-1990). The 21-year trajectories were assessed at seven study waves in which GHQ was assessed, beginning from wave 3 (1991-1994) and ending up to wave 11 (2012-2013).

\section{Assessment of prevalent CHD}

We ascertained the baseline CHD using data from the three first study waves (1985-1988 to 1991-1994). Non-fatal CHD included non-fatal MI or definite angina, defined according to the MONICA criteria, ${ }^{16}$ based on study ECG, hospital acute ECGs and cardiac enzymes. Angina was defined on the basis of clinical records and nitrate medication use, excluding cases based solely on self-reported data (the Rose Questionnaire) ${ }^{17}$ without clinical verification. Classification was carried out independently by two trained coders, with adjudication for any disagreements.

\section{Measurement of CHD risk factors}

We used data on CHD risk factors from the wave 3 (19911994) clinical examination. Smoking (yes/no) was based on survey questionnaire. Height was measured to the nearest $0.5 \mathrm{~cm}$. Weight was measured to the nearest $0.1 \mathrm{~kg}$. From these, body mass index (BMI) was measured and obesity was defined as a BMI $\geq 30 \mathrm{~kg} / \mathrm{m}^{2}$. Weekly alcohol use from survey questionnaire was used to categorise alcohol consumption as non-use, alcohol use within recommended limits (women: up to 14 drinks/week; men: up to 21 drinks/week) and alcohol use above recommended limits (women: $>14$ drinks/week; men: $>21$ drinks/week). ${ }^{18}$ Systolic and diastolic blood pressure was measured twice while seated after a $5 \mathrm{~min}$ rest, and means for the two measurements for systolic and diastolic blood pressure were used in the analyses. Information on antihypertensive medication was collected from survey responses. Hypertension was defined as either having systolic blood pressure $\geq 140 \mathrm{~mm} \mathrm{Hg}$, diastolic blood pressure $\geq 90 \mathrm{~mm} \mathrm{Hg}$ or as use of antihypertensive medication. Total cholesterol was assessed from blood serum samples, and hypercholesterolaemia was defined as total cholesterol $\geq 5.0 \mathrm{mmol} / \mathrm{L}$ or use of lipid-lowering drugs. To see whether the association between cholesterol level and trajectories of psychological distress is U shaped, ${ }^{19}$ an alternative threeclass formulation was computed: $<5.0,5.0-<6.5$ and $\geq 6.5 \mathrm{mmol} / \mathrm{L}$ (excluding the 52 participants with lipid-lowering drugs). Diabetes was defined as a fasting glucose $\geq 7.0 \mathrm{mmol} / \mathrm{L}$ or a 2 -hour postload glucose $\geq 11.1 \mathrm{mmol} / \mathrm{L}$ on the oral glucose tolerance test performed during the Whitehall study clinical screening or as physician-diagnosed diabetes or use of diabetes medication. $^{20}$

\section{Sociodemographic factors}

Age, sex and socioeconomic status were based on the survey questionnaire at wave 3 (if socioeconomic status was missing, it was derived from previous waves). Socioeconomic status was based on the civil service occupational grades. Employment grade in the Whitehall II study is a comprehensive marker of socioeconomic position and is related to salary, social status and level of responsibility at work. ${ }^{13}$ The civil service identifies 12 grades that comprise clerical assistant, clerical officer, executive officer, higher executive officer, senior executive officer and seven 'unified grades'. These were further grouped to the three categories: low, intermediate and high socioeconomic status. ${ }^{13}$

\section{Statistical analysis}

Trajectories of psychological distress were defined using groupbased trajectory models (GBTM), which identify clusters of individuals (trajectory groups) with a similar trajectory over time. ${ }^{21}$ GBTM is increasingly being applied to clinical research to map the developmental course of disease and to identify the number, shape and size of different (latent) trajectory groups in the data. We used the Bayesian Information Criteria and Akaike's information criterion to determine the optimal number of trajectories: lower absolute values correspond to better fit. ${ }^{21}$ We hypothesised a priori that there would be three to four latent trajectories, as suggested by other research on this topic. ${ }^{9}$

We applied multinomial regression analysis and expressed the results as ORs and their 95\% CIs, where all trajectory groups that we found were analysed together and persistently low was set as an outcome reference group against which the association with $\mathrm{CHD}$ and its risk factors were evaluated. The estimates were adjusted for age, sex and socioeconomic status. The full model also included CHD risk factors (smoking, high alcohol use, obesity, hypertension, hyperlipidaemia, diabetes and history of psychological distress) and a sensitivity analysis for the level of psychological distress at wave 3 (with four categories: 0, 1-5, 6-10 and $>10$ points). GBTM was performed using Stata V.13 and all other analyses using SAS V.9.4.

\section{RESULTS}

A four-trajectory solution with all trajectories non-linear yielded the best fit (see online supplementary table S1). Figure 1 presents the shape of each trajectory: predicted probabilities of group membership totalled $69 \%$ with persistently low, 13\% with persistently intermediate, $12 \%$ with intermediate to low and $7 \%$ with persistently high symptom trajectory. The corresponding proportions were $60 \%, 16 \%, 13 \%$ and $11 \%$ among 
Figure 1 Trajectories of psychological distress symptoms (General Health Questionnaire-30) among the Whitehall II study participants.

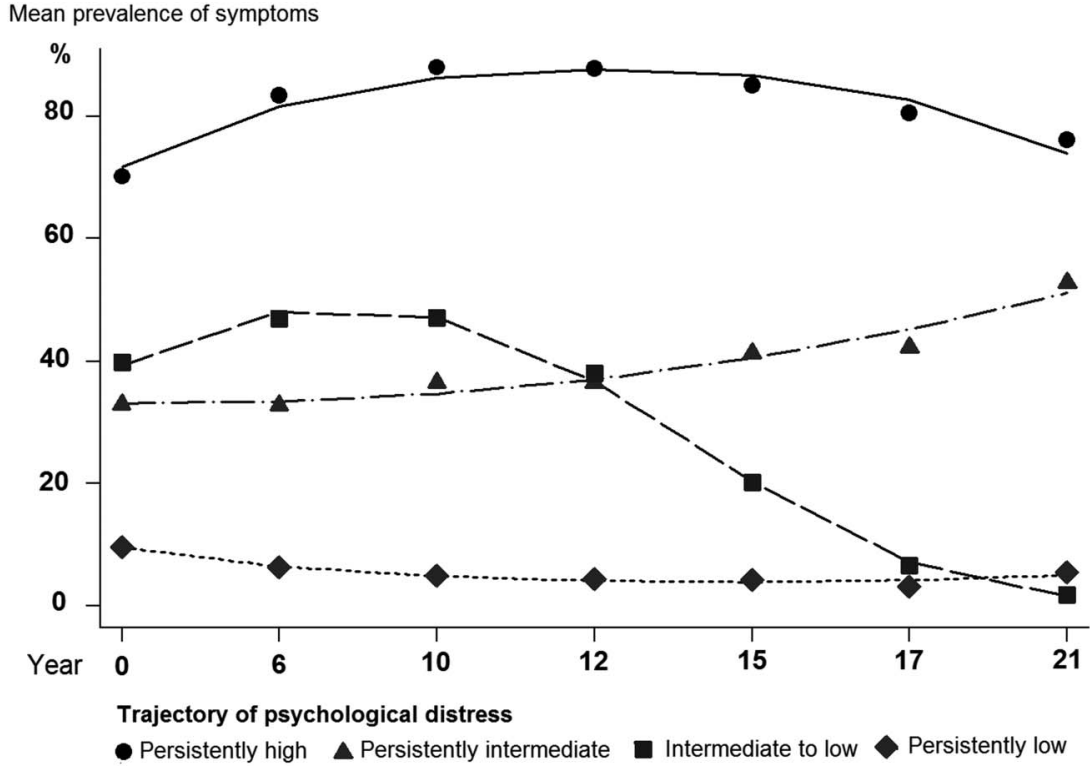

participants with $\mathrm{CHD} ; 63 \%, 15 \%, 12 \%$ and $10 \%$ among smokers and 63\%, 16\%, 12\% and $10 \%$ among obese participants.

Descriptive characteristics of the participants in table 1 by their membership of a psychological distress trajectory suggest that older participants, men and those with high socioeconomic status, non-smoking habit, normal weight and no CHD were overrepresented in the persistently low trajectory.

In table 2, we show the age sex and socioeconomic status adjusted associations from multinomial regression analyses of baseline sociodemographic characteristics and CHD risk factors with the psychological distress trajectories, setting persistently low as a reference group. Female sex, smoking and obesity were associated with the likelihood of being on persistently intermediate symptom trajectory; younger age and female sex were associated with intermediate to low trajectory and younger age, female sex, intermediate and low socioeconomic status, smoking and obesity were associated with persistently high symptom trajectory. The corresponding analyses in which all risk factors, baseline CHD and history of psychological distress were mutually adjusted, are presented in online supplementary table S2, with no remarkable changes in the estimates. Further adjustment for the level of psychological distress at baseline (wave 3) provided the following estimates: for smoking persistently intermediate $\mathrm{OR}=1.32$ (95\% CI 1.06 to 1.65$)$, intermediate to low $\mathrm{OR}=1.14 \quad(95 \% \quad \mathrm{CI} \quad 0.89$ to 1.46$)$ and persistently high $\mathrm{OR}=1.49$ (95\% CI 1.10 to 2.01 ); for obesity persistently intermediate $\mathrm{OR}=1.31$ (95\% CI 1.02 to 1.69$)$, intermediate to low $\mathrm{OR}=1.07 \quad(95 \%$ CI 0.80 to 1.43$)$ and persistently high $\mathrm{OR}=1.47$ (95\% CI 1.04 to 2.08 ).

Table 3 shows the association between CHD and trajectories of psychological distress. In analysis adjusted for sociodemographic factors and persistently low trajectory as a reference group, CHD was associated with ending up on persistently intermediate $(\mathrm{OR}=1.62,95 \% \mathrm{CI} 1.08$ to 2.41$)$, intermediate to low $(\mathrm{OR}=1.92,95 \%$ CI 1.24 to 2.99$)$ and persistently high trajectory $(\mathrm{OR}=2.41,95 \% \mathrm{CI} 1.49$ to 3.87$)$. After multivariable analysis in model 2, the significant associations with intermediate to low and persistently high were attenuated but remained significant while the association with persistently intermediate became non-significant. We further adjusted the models with the level of wave 3 psychological distress $(\mathrm{OR}=1.34,95 \%$ CI 0.88 to 2.05 for persistently intermediate; $\mathrm{OR}=1.67,95 \%$ CI 1.03 to 2.71 for intermediate to low and $\mathrm{OR}=1.80,95 \% \mathrm{CI} 1.02$ to 3.17 for persistently high, not shown in the table). We also found that there was no difference in the proportion of participants with missing data between trajectory groups (range 9\%$11 \%$ with missing data $p=0.113$ ). We also performed the age, sex and socioeconomic status adjusted analyses (which were all non-missing variables) among participants with missing data on other covariates $(n=7575)$ and found that the results for CHD, smoking and obesity were unchanged (not shown in the tables).

\section{DISCUSSION}

In this study of middle-aged men and women with up to seven repeated measurements of psychological distress over a maximum of 21 years, we identified four distinct trajectories of psychological distress: persistently low (the most common trajectory; $69 \%$ of the participants), persistently intermediate $(13 \%)$, intermediate to low $(12 \%)$ and persistently high $(7 \%)$ trajectories. These distributions are in line with previous studies which have found persistently low-symptom trajectories to be most common in midlife and old age. ${ }^{9}$

Most previous research in this field has examined whether depression is a risk factor for incident CHD or a risk factor for adverse cardiac outcomes among patients with $\mathrm{CHD} .^{2-5} 22-24$ Relatively little is known about CHD or its risk factors as predictors of depression or as in our study, more general common mental disorder, as indicated by psychological distress. Our findings are in line with the evidence supporting manifest CHD to be associated with the risk of depression..$^{5}$ Our findings also support previous studies which have shown the adverse symptom trajectories to be more common among women and individuals with low socioeconomic status. ${ }^{9} 25$ Our approach to $\mathrm{CHD}$ and its risk factors using long-term trajectory modelling of psychological distress is new. In the two previous studies on depression, CHD was self-reported and only in one study hypertension and obesity were clinically measured. ${ }^{10}{ }^{11}$ Both these studies included participants who were elderly ( $>65$ years) at baseline and followed for 20 years. The findings were inconsistent; in a study including only women, MI, hypertension and obesity predicted increasing and persistently high depressive symptom trajectories compared with persistently low, ${ }^{10}$ while 
Table 1 Descriptive characteristics of the participants at baseline by trajectories of psychological distress

\begin{tabular}{|c|c|c|c|c|c|}
\hline & \multicolumn{5}{|l|}{ Trajectories } \\
\hline & $\begin{array}{l}\text { All }(\mathrm{N}=6890) \text {, } \\
\mathrm{n}(\%)\end{array}$ & $\begin{array}{l}\text { 'Persistently } \\
\text { low' } \\
(\mathrm{N}=4731) \text {, } \\
\mathrm{n}(\%)\end{array}$ & $\begin{array}{l}\text { 'Persistently } \\
\text { intermediate' } \\
(\mathrm{N}=882), n \\
(\%)\end{array}$ & $\begin{array}{l}\text { 'Intermediate } \\
\text { to low' } \\
(\mathrm{N}=807), \mathrm{n} \\
(\%)\end{array}$ & $\begin{array}{l}\text { 'Persistently } \\
\text { high' } \\
(\mathrm{N}=470), \mathrm{n}(\%)\end{array}$ \\
\hline \multicolumn{6}{|l|}{ Age (years) } \\
\hline$<50$ & $3721(54.0)$ & $2376(50.2)$ & $477(54.1)$ & $573(71.0)$ & $295(62.7)$ \\
\hline$\geq 50$ & 3169 (45.9) & 2355 (49.8) & $405(45.9)$ & $234(29.0)$ & $175(37.2)$ \\
\hline \multicolumn{6}{|l|}{ Sex } \\
\hline Male & $4814(69.9)$ & 3447 (72.9) & $572(64.9)$ & $521(64.6)$ & $274(58.3)$ \\
\hline Female & $2076(30.1)$ & $1284(27.1)$ & $310(35.2)$ & $286(35.4)$ & $196(41.7)$ \\
\hline \multicolumn{6}{|l|}{ Socioeconomic status } \\
\hline High & $2730(39.6)$ & $1933(40.9)$ & $343(38.9)$ & $314(38.9)$ & $140(29.8)$ \\
\hline Intermediate & $3117(45.2)$ & $2096(44.3)$ & $398(45.1)$ & $389(48.2)$ & $234(49.8)$ \\
\hline Low & $1043(15.1)$ & $702(14.8)$ & $141(16.0)$ & $104(12.9)$ & $96(20.4)$ \\
\hline \multicolumn{6}{|l|}{ Smoking } \\
\hline No & $6023(87.4)$ & $4189(88.5)$ & $750(85.0)$ & $699(86.6)$ & $385(81.9)$ \\
\hline Yes & 867 (12.6) & $542(11.5)$ & $132(15.0)$ & $108(13.4)$ & $85(18.1)$ \\
\hline \multicolumn{6}{|l|}{ Alcohol use } \\
\hline No & $1274(18.5)$ & $855(18.1)$ & $176(20.0)$ & $133(16.5)$ & $110(23.4)$ \\
\hline Within recommended limits & $4525(65.7)$ & $3147(66.5)$ & $558(63.3)$ & $534(66.2)$ & $286(60.9)$ \\
\hline Above recommended limits & $1091(15.8)$ & 729 (15.4) & $148(16.8)$ & $140(17.4)$ & $74(15.7)$ \\
\hline \multicolumn{6}{|l|}{ Obesity } \\
\hline No & $6257(90.8)$ & 4335 (91.6) & $780(88.4)$ & $734(91.0)$ & $408(86.8)$ \\
\hline Yes & $633(9.2)$ & $396(8.4)$ & $102(11.6)$ & $73(9.1)$ & $62(13.2)$ \\
\hline \multicolumn{6}{|l|}{ Hypertension } \\
\hline No & $5488(79.7)$ & $3741(79.1)$ & $699(79.3)$ & $669(82.9)$ & $379(80.6)$ \\
\hline Yes & $1402(20.4)$ & $990(20.9)$ & $183(20.8)$ & $138(17.1)$ & $91(19.4)$ \\
\hline \multicolumn{6}{|c|}{ High total cholesterol $(\geq 5.0 \mathrm{mmol} / \mathrm{L})$} \\
\hline No & $601(8.7)$ & $402(8.5)$ & $66(7.5)$ & $88(10.9)$ & 45 (9.6) \\
\hline Yes & $6289(91.3)$ & 4329 (91.5) & $816(92.5)$ & $719(89.1)$ & $425(90.4)$ \\
\hline \multicolumn{6}{|l|}{ Total cholesterol level (mmol/L) } \\
\hline$<5.0$ & $601(8.8)$ & $402(8.6)$ & $66(7.6)$ & $88(11.0)$ & $45(9.7)$ \\
\hline $5.0-<6.5$ & 3050 (44.6) & $2066(44.0)$ & $380(43.5)$ & 381 (47.6) & $223(48.0)$ \\
\hline$\geq 6.5$ & 3187 (46.6) & $2232(47.5)$ & $427(48.9)$ & 331 (41.4) & $197(42.4)$ \\
\hline \multicolumn{6}{|l|}{ Diabetes } \\
\hline No & $6701(97.3)$ & $4597(97.2)$ & 857 (97.2) & $786(97.4)$ & $461(98.1)$ \\
\hline Yes & $183(2.7)$ & $134(2.8)$ & $25(2.8)$ & $21(2.6)$ & $9(1.9)$ \\
\hline \multicolumn{6}{|l|}{ Coronary heart disease } \\
\hline No & $6689(97.1)$ & 4610 (97.4) & $850(96.4)$ & $781(96.8)$ & $448(95.3)$ \\
\hline Yes & $201(2.9)$ & $121(2.6)$ & $32(3.6)$ & $26(3.2)$ & $22(4.7)$ \\
\hline
\end{tabular}

another, smaller study of men and women did not find any associations. $^{11}$

Our study adds new insight by using a relatively large dataset and clinically verified CHD in a middle-aged population. We found that participants with pre-existing CHD had a 1.9-fold increased risk of ending up on a persistently high and a 1.7-fold risk of intermediate to low, when compared with persistently low trajectory. There are at least two potential mechanisms that explain these results. According to the vascular depression hypothesis, ${ }^{5} 626$ long-term symptomatic trajectory may be the result of vascular pathology itself. However, in our cohort, smoking and obesity but not more direct indicators of vascular pathology, such as hypertension and hypercholesterolaemia, were associated with persistently high trajectory. Another viewpoint states that long-term trajectory of symptoms can be a component of prolonged adjustment disorder in response to a severe chronic disease and its impact on the quality of life. ${ }^{3} 27$ The association found between prevalent CHD and the development from intermediate to low trajectory may reflect this type of relatively short-term adjustment disorder.

Of the CHD risk factors, obesity and smoking were associated with persistently intermediate and persistently high symptom trajectories. Behaviour-related factors have rarely been investigated in this context and the findings from the few studies available are inconsistent. ${ }^{9} 1125$ Our results add evidence of the potential benefit of tackling obesity and smoking in the attempts to prevent long-lasting mental health problems. However, further intervention studies are needed to test whether these associations are causal. Further research should also examine the mechanisms, such as systemic inflammation, underlying the link between CHD, obesity, smoking and mental health trajectories. Although we found limited support for the vascular origin hypothesis, it is important to note that CHD and the risk factors were based on one-time assessments at baseline and we did not account for time-varying changes in them. They may change over time, for example, due to new events and new 
Table 2 Multinomial logistic regression analysis for the associations of sociodemographic factors and cardiovascular risk factors at baseline with trajectories of psychological distress

\begin{tabular}{|c|c|c|c|}
\hline & $\begin{array}{l}\text { 'Persistently intermediate' } \\
\text { versus 'persistently low' } \\
\text { OR }(95 \% \mathrm{Cl})^{*}\end{array}$ & $\begin{array}{l}\text { 'Intermediate to low' versus } \\
\text { 'persistently low' } \\
\text { OR }(95 \% \mathrm{Cl})^{*}\end{array}$ & $\begin{array}{l}\text { 'Persistently high' versus } \\
\text { 'persistently low' } \\
\text { OR }(95 \% \mathrm{Cl})^{*}\end{array}$ \\
\hline \multicolumn{4}{|l|}{ Age (years) } \\
\hline$<50$ & 1.00 & 1.00 & 1.00 \\
\hline$\geq 50$ & $0.90(0.77$ to 1.07$)$ & $0.41(0.33$ to 0.50$)$ & $0.55(0.43$ to 0.70$)$ \\
\hline \multicolumn{4}{|l|}{ Sex } \\
\hline Male & 1.00 & 1.00 & 1.00 \\
\hline Female & 1.53 (1.29 to 1.81$)$ & 1.69 (1.42 to 2.01$)$ & 1.80 (1.45 to 2.24$)$ \\
\hline \multicolumn{4}{|l|}{ Socioeconomic status } \\
\hline High & 1.00 & 1.00 & 1.00 \\
\hline Intermediate & $0.98(0.83$ to 1.15$)$ & $0.99(0.84$ to 1.17$)$ & 1.34 (1.07 to 1.67$)$ \\
\hline Low & $0.90(0.71$ to 1.15$)$ & $0.78(0.60$ to 1.01$)$ & $1.47(1.08$ to 2.00$)$ \\
\hline \multicolumn{4}{|l|}{ Smoking } \\
\hline No & 1.00 & 1.00 & 1.00 \\
\hline Yes & 1.34 (1.09 to 1.65$)$ & 1.16 (0.93 to 1.46$)$ & 1.55 (1.20 to 2.01$)$ \\
\hline \multicolumn{4}{|l|}{ Alcohol use } \\
\hline Within recommended limits & 1.00 & 1.00 & 1.00 \\
\hline No use & 1.11 (0.91 to 1.35$)$ & $0.92(0.75$ to 1.14$)$ & 1.22 (0.96 to 1.56$)$ \\
\hline Above recommended limits & $1.16(0.95$ to 1.42$)$ & $1.08(0.88$ to 1.33$)$ & 1.16 (0.88 to 1.52$)$ \\
\hline \multicolumn{4}{|l|}{ Obesity } \\
\hline No & 1.00 & 1.00 & 1.00 \\
\hline Yes & 1.35 (1.07 to 1.71$)$ & $1.07(0.82$ to 1.40$)$ & 1.49 (1.11 to 1.99$)$ \\
\hline \multicolumn{4}{|l|}{ Hypertension } \\
\hline No & 1.00 & 1.00 & 1.00 \\
\hline Yes & 1.06 (0.89 to 1.27$)$ & 0.97 (0.79 to 1.18$)$ & 1.06 (0.83 to 1.36$)$ \\
\hline \multicolumn{4}{|c|}{ High total cholesterol ( $\geq 5.0 \mathrm{mmol} / \mathrm{L})$} \\
\hline No & 1.00 & 1.00 & 1.00 \\
\hline Yes & 1.23 (0.93 to 1.62$)$ & $0.98(0.76$ to 1.26$)$ & $1.05(0.76$ to 1.46$)$ \\
\hline \multicolumn{4}{|l|}{ Total cholesterol level (mmol/L) } \\
\hline$<5.0$ & 1.00 & 1.00 & 1.00 \\
\hline $5.0-<6.5$ & $1.18(0.89$ to 1.56$)$ & $1.00(0.77$ to 1.29$)$ & $1.10(0.78$ to 1.55$)$ \\
\hline$\geq 6.5$ & $1.28(0.96$ to 1.70$)$ & $0.95(0.72$ to 1.23$)$ & $0.99(0.70$ to 1.41$)$ \\
\hline \multicolumn{4}{|l|}{ Diabetes } \\
\hline No & 1.00 & 1.00 & 1.00 \\
\hline Yes & 1.07 (0.69 to 1.65$)$ & $1.16(0.72$ to 1.86$)$ & $0.73(0.37$ to 1.46$)$ \\
\hline
\end{tabular}

${ }^{*}$ Adjusted for age, sex and socioeconomic status.

treatment practices. As lipid-lowering drugs became increasingly common over the follow-up, it might have diluted the association with hypercholesterolaemia.

A major strength of this study is a long-term follow-up of psychological distress with up to seven measurement points and a valid, clinically ascertained CHD at the baseline. Data on BMI, hypertension, hypercholesterolaemia and diabetes were based on clinical examinations. The study also has limitations. The GHQ-30 is a screening instrument, designed to capture symptoms of depression, anxiety, insomnia and social dysfunction rather than providing a clinical diagnosis of depressive disorders. However, it has been shown to have high validity for depression in the present cohort. ${ }^{15}$ For elderly cohorts, these types of non-specific instruments have been suggested to be more suitable than those assessing clinical diagnoses of depressive disorder because the manifest disease is often non-specific and multimorbid. ${ }^{12}$ Although this study provides a novel approach to research on long-term associations between CHD and psychological distress, a replication with a larger number of baseline CHD cases is needed.
Loss to follow-up may also have affected the trajectories estimated. In the present cohort, those who died had an average of four measurements while the mean number of measurements in the total cohort was six out of the maximum of seven. The mean number of measurements during follow-up was similar (6.0, $\mathrm{p}=0.520)$ among baseline distress cases and non-cases although the CHD cases had fewer (5.7) measurements than non-cases $(6.0 ; p=0.003)$. Because the number of assessments was satisfactory in all groups, we believe that these differences are not likely to have introduced major bias. In addition, while GBTM identifies a certain number of discrete latent trajectories in observed data, it cannot prove that such discrete trajectories actually exist and remain as observed over time. GBTM also has difficulty in detecting subgroups that represent a very small portion of the population which, however, was not an issue in our study. Furthermore, factors that were not measured in our study, such as severity of disease, individual coping strategies ${ }^{28}$ and cardiac rehabilitation interventions among individuals with $\mathrm{CHD}^{24}$ may affect the mental health prognosis. Further studies should also examine whether the associations are bidirectional, 
Table 3 Multinomial logistic regression analysis for the association between coronary heart disease (CHD) at baseline and trajectories of psychological distress

\begin{tabular}{llll}
\hline $\begin{array}{l}\text { CHD at } \\
\text { baseline }\end{array}$ & $\begin{array}{l}\text { 'Persistently } \\
\text { intermediate' versus } \\
\text { 'persistently low' }\end{array}$ & $\begin{array}{l}\text { 'Intermediate to } \\
\text { low' versus } \\
\text { 'persistently low' }\end{array}$ & $\begin{array}{l}\text { 'Persistently high' } \\
\text { versus 'persistently } \\
\text { low' }\end{array}$ \\
\hline $\begin{array}{l}\text { Model } 1 \text { * } \\
\text { No CHD }\end{array}$ & 1.00 & 1.00 & 1.00 \\
$\begin{array}{l}\text { CHD } \\
\text { Model 2† } \\
\text { No CHD }\end{array}$ & $1.62(1.08$ to 2.41$)$ & $1.92(1.24$ to 2.99$)$ & $2.41(1.49$ to 3.87$)$ \\
CHD & $1.38(0.91$ to 2.09$)$ & $1.70(1.08$ to 2.68$)$ & $1.92(1.16$ to 3.19) \\
\hline
\end{tabular}

${ }^{*}$ Adjusted for age, sex and socioeconomic status.

†Adjusted for age, sex, socioeconomic status, smoking, obesity, alcohol use,

hypertension, cholesterol, diabetes and history of psychological distress.

that is, whether being on a long-term trajectory of symptoms predict incident CHD or whether a combination of long-term symptoms and CHD increases the risk of premature death. ${ }^{29}$ Finally, as the Whitehall II study is an occupational white-collar cohort, replications with general populations are also needed.

We have shown that over two-thirds of middle-aged participants followed trajectories through old age that were characterised by low probability of psychological distress while $7 \%$ were on a trajectory of persistent distress. This study is in line with the current guidelines which highlight the assessment of mental health among patients with $\mathrm{CHD} .{ }^{30}$ Clinicians should be aware of the potential long-lasting associations of CHD, obesity and smoking as risk factors for prolonged psychological distress.

Key messages

What is already known on this subject?

- Coronary heart disease (CHD) and its risk factors have been found to predict symptoms of mental disorders, particularly depression.

- Their associations with long-term trajectories of mental ill health from midlife to old age remain unclear.

\section{What might this study add?}

- Trajectory analyses over 21 years showed that CHD was associated with a 1.9-fold, smoking with a 1.6-fold and obesity with a 1.5 -fold likelihood of persistent psychological distress trajectory from midlife to old age.

\section{How might this impact on clinical practice?}

- Clinicians should be aware that persons who smoke, have CHD or are obese are at increased risk of having long-lasting psychological distress symptoms.

Contributors MV is responsible for the overall content as a guarantor, contributed to the conception and design of the work, data analysis and drafting the manuscript; ME contributed to the conception and design of the work, data analysis and revising the manuscript critically for important intellectual content; $\mathrm{KJ}$ contributed to the design of the work, data analysis and revising the manuscript; GDB and AS-M contributed to the design of the work, interpretation of data and revising the manuscript; MK contributed to the conception and design of the work, interpretation of data and revising the manuscript. All authors approved the final version to be published and have agreement to be accountable for all aspects of the work in ensuring that questions related to the accuracy or integrity of any part of the work are appropriately investigated and resolved.

Funding The Whitehall II Study is supported by grants from the Medical Research Council (K013351), the British Heart Foundation, the National Heart Blood and Lung Institute, National Institutes of Health (NIH) (R01HL036310) and the National Institute of Aging, NIH (R01AG013196 and R01AG034454). MV is supported by the Academy of Finland $(258598,92824)$, ME by the Academy of Finland (265977) and MK by the UK Medical Research Council (K013351), NordForsk, the Nordic Council of Ministers (grant 75021) and Finnish Work Environment Foundation.

\section{Competing interests None.}

Ethics approval The University College London Medical School and the NHS London-Harrow Health Research Authority committees on the ethics of human research.

Provenance and peer review Not commissioned; externally peer reviewed.

Open Access This is an Open Access article distributed in accordance with the terms of the Creative Commons Attribution (CC BY 4.0) license, which permits others to distribute, remix, adapt and build upon this work, for commercial use, provided the original work is properly cited. See: http://creativecommons.org/licenses/ by/4.0/

\section{REFERENCES}

1 Kessler RC, Angermeyer M, Anthony JC, et al. Lifetime prevalence and age-of-onset distributions of mental disorders in the World Health Organization's World Mental Health Survey Initiative. World Psychiatry 2007;6:168-76.

2 Wu Q, Kling JM. Depression and the risk of myocardial infarction and coronary death: a meta-analysis of prospective cohort studies. Medicine (Baltimore) 2016;95: e2815.

3 Hare DL, Toukhsati SR, Johansson P, et al. Depression and cardiovascular disease: a clinical review. Eur Heart J 2014;35:1365-72.

4 Huang CQ, Dong BR, Lu ZC, et al. Chronic diseases and risk for depression in old age: a meta-analysis of published literature. Ageing Res Rev 2010;9:131-41.

5 Valkanova V, Ebmeier KP. Vascular risk factors and depression in later life: a systematic review and meta-analysis. Biol Psychiatry 2013;73:406-13.

6 Alexopoulos GS, Meyers BS, Young RC, et al. 'Vascular depression' hypothesis. Arch Gen Psychiatry 1997;54:915-22.

7 Pietrzak RH, Kinley J, Afifi TO, et al. Subsyndromal depression in the United States: prevalence, course, and risk for incident psychiatric outcomes. Psychol Med 2013;43:1401-14.

8 Russ TC, Stamatakis E, Hamer M, et al. Association between psychological distress and mortality: individual participant pooled analysis of 10 prospective cohort studies. BMJ 2012;345:e4933.

9 Musliner KL, Munk-Olsen T, Eaton WW, et al. Heterogeneity in long-term trajectories of depressive symptoms: Patterns, predictors and outcomes. J Affect Disord 2016;192:199-211.

10 Byers AL, Vittinghoff $E$, Lui LY, et al. Twenty-year depressive trajectories among older women. Arch Gen Psychiatry 2012;69:1073-9.

11 Montagnier D, Dartigues JF, Rouillon F, et al. Ageing and trajectories of depressive symptoms in community-dwelling men and women. Int J Geriatr Psychiatry 2014;29:720-9.

12 Bryant C. Anxiety and depression in old age: challenges in recognition and diagnosis. Int Psychogeriatr 2010;22:511-13.

13 Marmot M, Brunner E. Cohort profile: the Whitehall II study. Int J Epidemiol 2005:34:251-6

14 Goldberg DP. The detection of psychiatric illness by questionnaire. London: Oxford University Press, 1972.

15 Head J, Stansfeld SA, Ebmeier KP, et al. Use of self-administered instruments to assess psychiatric disorders in older people: validity of the General Health Questionnaire, the Center for Epidemiologic Studies Depression Scale and the self-completion version of the revised Clinical Interview Schedule. Psychol Med 2013;43:2649-56.

16 Tunstall-Pedoe H, Kuulasmaa K, Amouyel P, et al. Myocardial infarction and coronary deaths in the World Health Organization MONICA Project. Registration procedures, event rates, and case-fatality rates in 38 populations from 21 countries in four continents. Circulation 1994;90:583-612.

17 Rose GA, Blackburn H, Gillum RF, et al. Cardiovascular survey methods, 2nd edn. Geneva: World Health Organization, 1982.

18 Virtanen M, Jokela M, Nyberg ST, et al. Long working hours and alcohol use: systematic review and meta-analysis of published studies and unpublished individual participant data. BMJ 2015;350:g7772.

19 De Berardis D, Marini S, Piersanti M, et al. The relationships between cholesterol and suicide: an update. ISRN Psychiatry 2012;2012:387901.

20 Tabák AG, Jokela M, Akbaraly TN, et al. Trajectories of glycaemia, insulin sensitivity, and insulin secretion before diagnosis of type 2 diabetes: an analysis from the Whitehall II study. Lancet 2009;373:2215-21. 
21 Nagin DS. Analyzing developmental trajectories: a semiparametric, group-based approach. Psychol Methods 1999;4:139-57.

22 Gan $Y$, Gong $Y$, Tong $X$, et al. Depression and the risk of coronary heart disease: a meta-analysis of prospective cohort studies. BMC Psychiatry $2014 ; 14: 371$.

23 Meijer A, Conradi HJ, Bos EH, et al. Adjusted prognostic association of depression following myocardial infarction with mortality and cardiovascular events: individual patient data meta-analysis. Br J Psychiatry 2013:203:90-102.

24 Whalley B, Rees K, Davies $P$, et al. Psychological interventions for coronary heart disease. Cochrane Database Syst Rev 2011;(8):CD002902.

25 Melchior M, Chastang JF, Head J, et al. Socioeconomic position predicts long-term depression trajectory: a 13-year follow-up of the GAZEL cohort study. Mol Psychiatry 2013;18:112-21.

26 Kivimäki M, Shipley MJ, Allan $\mathrm{CL}$, et al. Vascular risk status as a predictor of later-life depressive symptoms: a cohort study. Biol Psychiatry 2012;72:324-30.
27 de Jonge $\mathrm{P}$, Spijkerman TA, van den Brink $\mathrm{RH}$, et al. Depression after myocardial infarction is a risk factor for declining health related quality of life and increased disability and cardiac complaints at 12 months. Heart 2006;92:32-9.

28 Kroemeke A. Depressive symptom trajectories over a 6-year period following myocardial infarction: predictive function of cognitive appraisal and coping. J Behav Med 2016:39:181-91.

29 Nabi H, Shipley MJ, Vahtera J, et al. Effects of depressive symptoms and coronary heart disease and their interactive associations on mortality in middle-aged adults: the Whitehall II cohort study. Heart 2010;96:1645-50.

30 Piepoli MF, Hoes AW, Agewall S, et al. 2016 European Guidelines on cardiovascular disease prevention in clinical practice: The Sixth Joint Task Force of the European Society of Cardiology and other societies on cardiovascular disease prevention in clinical practice (constituted by representatives of 10 societies and by invited experts) developed with the special contribution of the European Association for Cardiovascular Prevention \& Rehabilitation (EACPR). Eur Heart J 2016;37:2315-81. 